\title{
Variabilidade morfológica da coleção de germoplasma de batata-doce da Embrapa-Centro Nacional de Pesquisa de Hortaliças ${ }^{(1)}$
}

\author{
Patrícia Silva Ritschel(2) e Zósimo Huamán ${ }^{(3)}$
}

Resumo - A coleção de germoplasma de batata-doce (Ipomoea batatas L.), mantida pela EmbrapaCentro Nacional de Pesquisa de Hortaliças, foi reunida por meio de expedições de coleta e pela duplicação da coleção anteriormente mantida pela Embrapa-Centro Nacional de Pesquisa de Mandioca e Fruticultura. O objetivo deste trabalho foi descrever e analisar a variabilidade morfológica mantida nessa coleção. Foram avaliados 324 acessos nativos de batata-doce, utilizando-se 25 características morfológicas. Foi possível identificar 256 tipos morfológicos, sendo 223 acessos com morfologia única e 33 grupos de acessos morfologicamente duplicados. Cerca de $20 \%$ da coleção consistia de duplicações. Com base na estimativa da diversidade fenotípica mantida na coleção de cada descritor utilizado, considerou-se que a coleção apresenta um nível de polimorfismo alto. Os resultados obtidos foram discutidos em termos de sua utilização na organização da coleção, no planejamento da coleção in vitro dos campos de produção de sementes botânicas e das atividades de caracterização molecular, e no gerenciamento deste recurso genético em âmbito nacional.

Termos para indexação: Ipomoea batatas, recursos genéticos, polimorfismo genético.

\section{Morphological variability of the sweetpotato germplasm collection of the Embrapa-Centro Nacional de Pesquisa de Hortaliças}

Abstract - The sweetpotato germplasm collection conserved by Embrapa-Centro Nacional de Pesquisa de Hortaliças was gathered by means of recollection expeditions and the duplication of the collection formerly maintained by Embrapa-Centro Nacional de Pesquisa de Mandioca e Fruticultura. The purpose of this paper was to describe and to analyze the morphological variability maintained in that collection. Three-hundred and twenty-four native accessions were evaluated, using 25 morphological characteristics. It was possible to identify 256 morphological types; 223 accessions presenting unique morphology and 33 groups of morphologically identical accessions. About $20 \%$ of the collection were made of duplications. Based on the assessment of the phenotypic diversity maintained in this collection for each descriptor used, it was considered that the collection presents a high level of polymorphism. The results were discussed in relation to their use on the organization of the germplasm collection, on the planning of the in vitro collection, of seed production fields and of the molecular characterization activities and on the management of this genetic resource at national level.

Index terms: Ipomoea batatas, genetic resources, genetic polymorphism.

\section{Introdução}

A modernização da agricultura e o conseqüente êxodo rural têm provocado a perda de diversidade genética de culturas, como a batata-doce (Ipomoea

\footnotetext{
(1) Aceito para publicação em 10 de agosto de 2001 .

(2) Embrapa-Centro Nacional de Pesquisa de Hortaliças, Caixa Postal 218, CEP 70359-970 Brasília, DF E-mail: patricia@cnph.embrapa.br

(3) Centro Internacional de la Papa, Apartado Postal 1558, Lima, Peru. E-mail: z.huaman@cgiar.org
}

batatas L.) (Austin, 1988; Huamán \& Puente, 1988; Horton et al., 1989). Algumas espécies do gênero Ipomoea, seção batatas, ocorrem no Brasil (Austin, 1988), o que inclui parte do País entre as regiões que apresentam variabilidade na cultura. Com o objetivo de conservar a diversidade genética da batata-doce, várias expedições de coleta deste recurso genético foram realizadas no final da década de 80 , resultando na reunião de várias coleções de germoplasma. A coleção mantida pela Embrapa-Centro Nacional de Pesquisa de Hortaliças (CNPH) foi reunida em expedições de coleta realizadas em conjunto pela 
Embrapa-Centro Nacional de Pesquisa de Hortaliças, Embrapa-Centro Nacional de Recursos Genéticos e Biotecnologia, Centro Internacional de La Papa (CIP), e pela duplicação da coleção mantida pela Embrapa-Centro Nacional de Pesquisa de Mandioca e Fruticultura. O material foi coletado em feiras livres, mercados, campos de produtores, e em algumas reservas indígenas (Miranda \& França, 1987; Ritschel et al., 1999a).

Considerando-se a maneira como este material foi reunido e a forma de multiplicação da cultura da batata-doce, através de propagação vegetativa, estimase que parte dos acessos mantidos em coleções sejam duplicatas. A ocorrência de duplicatas não identificadas em Bancos de Germoplasma encarece e dificulta a manutenção adequada do material, gerando problemas relacionados à organização e ao acesso de usuários potenciais ao recurso genético (Frankel \& Bennet, 1970; Strauss et al., 1989; Beuselinck \& Steiner, 1992). Assim, a caracterização de coleções de germoplasma vem sendo bastante enfatizada (Peeters \& Williams, 1984; Peeters \& Martinelli, 1989; Beuselinck \& Steiner, 1992; Kresovich \& McFerson, 1992).

A caracterização morfológica de um banco de germoplasma é normalmente a forma mais acessível de quantificar sua diversidade genética e é bastante utilizada (Halcomb et al., 1977; Perry \& McIntosh, 1991; Singh et al., 1991; Kresovich \& McFerson, 1992; Jana \& Singh, 1993; Li et al., 1995; Rabbani et al., 1998). Descritores morfológicos específicos para a cultura da batata-doce estão disponíveis (Huamán, 1991). Estimativas relativamente altas de herdabilidade de algumas das características utilizadas como descritores de batata-doce (Jones, 1969; Jones et al., 1969) aumentam a confiança na utilização dessas variáveis no processo de caracterização morfológica.

O objetivo deste trabalho foi avaliar a diversidade fenotípica da coleção de germoplasma de batatadoce da Embrapa-Centro Nacional de Pesquisa de Hortaliças (CNPH) por meio de descritores morfológicos.

\section{Material e Métodos}

O Banco Ativo de Germoplasma de batata-doce é atualmente formado pela coleção reunida pela Embrapa-
CNPH e também por duplicações das coleções mantidas pela Empresa de Pesquisa Agropecuária e Difusão de Tecnologia de Santa Catarina (Epagri), Empresa Pernambucana de Pesquisa Agropecuária (IPA) e pela Empresa de Pesquisa Agropecuária do Rio de Janeiro (Pesagro). Neste trabalho, foram caracterizados e analisados 324 acessos nativos de batata-doce pertencentes à coleção reunida pelo CNPH, coletados em todas as regiões brasileiras (Ritschel et al., 1999a).

Para a caracterização morfológica, os acessos foram plantados em maio/1997 e janeiro/1998, em parcelas de dez plantas. Com base em resultados parciais de avaliações anteriores, a disposição no campo foi planejada de forma que acessos morfologicamente semelhantes ficassem lado a lado, facilitando a caracterização comparativa desses acessos. Foram utilizados 25 descritores morfológicos: arquitetura da planta, comprimento da rama principal, comprimento e diâmetro do entrenó, cores predominante e secundária da rama, tipo de pubescência da rama, tamanho e forma geral da folha, tipo e número de lóbulos e formato do lóbulo central, pigmentação de nervuras abaxiais, cores das folhas madura e imatura, comprimento e pigmentação do pecíolo, formato da raiz e presença de defeitos, cores principal e secundária da película externa da raiz e intensidade da cor principal, cores principal e secundária da polpa da raiz e padrão de distribuição da cor secundária. A descrição de cada item utilizado na caracterização morfológica de batata-doce está disponível em Huamán (1991,1992). As escalas de notas referentes a cada descritor são apresentadas na Tabela 1.

As características vegetativas foram avaliadas três meses após o plantio, e as características das raízes, aos cinco meses. Para facilitar a caracterização das raízes, elas foram colhidas, etiquetadas, lavadas e agrupadas considerando-se as cores principal e secundária da película, o formato e presença de defeitos e as cores da polpa, e sua distribuição. As características foram observadas, e suas notas, registradas em uma planilha. As descrições morfológicas de cada um dos acessos, utilizadas para as análises realizadas neste trabalho, são apresentadas em Ritschel et al. (1999a).

Para o cálculo dos coeficientes de similaridade fenotípica entre os acessos utilizou-se o programa NTSYS, e os dados, analisados por meio do algoritmo UPGMA e a análise de coordenadas principais. Os coeficientes de similaridade foram calculados por Ligação Simples, conforme a fórmula citada por Rohlf (1992) e Cruz \& Regazzi (1994):

$\mathrm{SM}=(\mathrm{a}+\mathrm{d}) /(\mathrm{a}+\mathrm{b}+\mathrm{c}+\mathrm{d})$

onde: SM é o coeficiente de similaridade (Ligação Simples); a, o número de coincidências positivas; b e c, os números de não-coincidências; $d$, o número de coincidências negativas. 
Estas análises permitiram agrupar os acessos morfologicamente semelhantes e identificar os grupos morfológicos de acessos duplicados.
Como forma de estimar a variabilidade fenotípica mantida na coleção, foram também calculados os índices de diversidade de Shannon-Weaver $(\mathrm{H})$, para cada descritor

Tabela 1. Características utilizadas como descritores morfológicos de acessos de batata-doce (Huamán, 1991).

\begin{tabular}{|c|c|c|c|c|c|}
\hline Características & Notas & Características & Notas & Características & Notas \\
\hline 1. Enroscamento do ápice & & Dentado & 1 & Longa elíptica & 8 \\
\hline Não enroscante & 3 & Triangular & 2 & Longa irregular ou curvada & 9 \\
\hline Ligeiramente enroscante & 5 & Semi-circular & 3 & 19. Defeitos da superfície da raiz & \\
\hline Moderadamente enroscante & 7 & Semi-elíptico & 4 & Ausente & 0 \\
\hline Enroscante & 9 & Elíptico & 5 & Película tipo jacaré & 1 \\
\hline Muito enroscante & & Lanceolado & 6 & Veias & 2 \\
\hline 2. Comprimento de ramas principais & & Oblanceolado & 7 & Constrições horizontais rasas & 3 \\
\hline Ereta $(<75 \mathrm{~cm})$ & 3 & Linear (grosso) & 8 & Constrições horizontais profundas & 4 \\
\hline Semi-ereta $(75-150 \mathrm{~cm})$ & 5 & Linear (fino) & 9 & Fendas longitudinais rasas & 5 \\
\hline Rasteira $(151-250 \mathrm{~cm})$ & 7 & 12. Tamanho da folha madura & & Fendas longitudinais profundas & 6 \\
\hline Externamente rasteira $(>250 \mathrm{~cm})$ & 9 & Pequena $(<8 \mathrm{~cm})$ & 3 & Constrições profundas e fendas profundas & 7 \\
\hline 3. Comprimento do entrenó & & Média $(8-15 \mathrm{~cm})$ & 5 & Outras (especificar) & 8 \\
\hline Muito curto $(<3 \mathrm{~cm})$ & 1 & Grande $(16-25 \mathrm{~cm})$ & 7 & 20. Cor predominante da película & \\
\hline Curto $(3-5 \mathrm{~cm})$ & 3 & Muito grande (> $25 \mathrm{~cm})$ & 9 & Branca & 1 \\
\hline Intermediário $(6-9 \mathrm{~cm})$ & 5 & 13. Pigmentação das nervuras & & Creme & 2 \\
\hline Longo $(10-12 \mathrm{~cm})$ & 7 & Amarelas & 1 & Amarela & 3 \\
\hline Muito longo $(>12 \mathrm{~cm})$ & & Verdes & 2 & Laranja & 4 \\
\hline 4. Diâmetro do entrenó & & Manchas roxas na base da nervura principal & 3 & Marrom-alaranjada & 5 \\
\hline Muito fino $(<4 \mathrm{~mm})$ & 1 & Manchas roxas em várias nervuras & 4 & Rosa & 6 \\
\hline Fino $(4-6 \mathrm{~mm})$ & 3 & Nervura principal parcialmente roxa & 5 & Vermelha & 7 \\
\hline Intermediário (7-9 mm) & 5 & Nervura principal predominante ou totalmente roxa & 6 & Roxa-avermelhada & 8 \\
\hline Grosso $(10-12 \mathrm{~mm})$ & 7 & Todas as nervuras parcialmente roxas & 7 & Roxa escura & 9 \\
\hline Muito grosso (> $12 \mathrm{~mm}$ ) & 9 & Todas as nervuras predominante ou parcialmente roxas & 8 & 21. Intensidade da cor predominante & \\
\hline 5. Cor predominante da rama & & Superfície adaxial e nervuras totalmente roxas & 9 & Pálida & 1 \\
\hline Verde & 1 & 14. Cor da folha madura & & Intermediária & 2 \\
\hline Verde com poucas manchas roxas & 3 & Verde-amarelada & 1 & Escura & 3 \\
\hline Verde com muitas manchas roxas & 4 & Verde & 2 & 22. Cor secundária da película & \\
\hline Verde com muitas manchas roxas escuras & 5 & Verde com extremidade roxa & 3 & Ausente & 0 \\
\hline Predominantemente roxa & 6 & Verde-acinzentado & 4 & Branca & 1 \\
\hline Predominantemente roxa escura & 7 & Verde com nervuras roxas na superfície abaxial & 5 & Creme & 2 \\
\hline Totalmente roxa & 8 & Fracamente roxa & 6 & Amarela & 3 \\
\hline Totalmente roxa escura & 9 & Predominantemente roxa & 7 & Laranja & 4 \\
\hline 6. Cor secundária da rama & & Verde na parte abaxial, roxa na parte adaxial & 8 & Marron-alaranjada & 5 \\
\hline Ausente & 0 & Roxas em ambas superfícies & 9 & Rosa & 6 \\
\hline Base verde & 1 & 15. Cor da folha imatura & & Vermelha & 7 \\
\hline Ponta verde & 2 & Verde-amarelada & 1 & Roxa-avermelhada & 8 \\
\hline Nós verdes & 3 & Verde & 2 & Roxa escura & 9 \\
\hline Base roxa & 4 & Verde com extremidade roxa & 3 & 23. Cor predominante da polpa & \\
\hline Ponta roxa & 5 & Verde-acinzentado & 4 & Branca & 1 \\
\hline Nós roxos & 6 & Verde com nervuras roxas na superfície abaxial & 5 & Creme & 2 \\
\hline Outros (especificar) & 7 & Fracamente roxa & 6 & Creme escura & 3 \\
\hline 7. Tipo de pubescência da rama & & Predominantemente roxa & 7 & Amarelo-pálida & 4 \\
\hline Ausente & 0 & Verde na parte abaxial, roxa na parte adaxial & 8 & Amarelo escura & 5 \\
\hline Esparsa & 3 & Roxas em ambas superfícies & 9 & Laranja-pálida & 6 \\
\hline Moderada & 5 & 16. Comprimento do pecíolo & & Laranja intermediária & 7 \\
\hline Densa & 7 & Muito curto $(<10 \mathrm{~cm})$ & 1 & Laranja escura & 8 \\
\hline 8. Forma geral da folha & & Curto $(12-20 \mathrm{~cm})$ & 3 & Fortemente pigmentada com antocianinas & 9 \\
\hline Arredondada & 1 & Intermediário $(21-30 \mathrm{~cm})$ & 5 & 24. Cor secundária da polpa & \\
\hline Reniforme & 2 & Longo $(31-40 \mathrm{~cm})$ & 7 & Ausente & 0 \\
\hline Cordata & 3 & Muito longo (> $40 \mathrm{~cm})$ & 9 & Branca & 1 \\
\hline Triangular & 4 & 17. Pigmentação do pecíolo & & Creme & 2 \\
\hline Hastada & 5 & Verde & 1 & Amarela & 3 \\
\hline Lobada & 6 & Verde com roxo próximo à rama & 2 & Laranja & 4 \\
\hline Quase dividida & 7 & Verde com roxo próximo à folha & 3 & Rosa & 5 \\
\hline 9. Tipos de lóbulos da folha & & Verde com roxo nas duas extremidades & 4 & Vermelha & 6 \\
\hline Sem lóbulos laterais (inteira) & 0 & Verde com manchas roxas & 5 & Roxa-avermelhada & 7 \\
\hline Muito superficiais & 1 & Verde com faixas roxas & 6 & Roxa & 8 \\
\hline Superficiais & 3 & Roxo com verde próximo à folha & 7 & Roxa escura & 9 \\
\hline Moderados & 5 & Alguns pecíolos verdes; outros roxos & 8 & 25. Distrib. da cor sec. da polpa & \\
\hline Profundos & 7 & Predominante ou totalmente roxo & 9 & Ausente & 0 \\
\hline Muito profundos & 9 & & & Anel estreito no córtex & 1 \\
\hline 10. Número de lóbulos da folha & & 18. Forma das raízes & & Anel largo no córtex & 2 \\
\hline Um & 1 & Redonda & 1 & Pontos espalhados na polpa & 3 \\
\hline Três & 3 & Redonda elíptica & 2 & Anel fino na polpa & 4 \\
\hline Cinco & 5 & Elíptica & 3 & Anel largo na polpa & 5 \\
\hline Sete & 7 & Ovada & 4 & Anel e outras áreas da polpa & 6 \\
\hline Muitos & 9 & Obovada & 5 & Em secções longitudinais & 7 \\
\hline 11. Forma do lóbulo central & & Oblonga & 6 & Cobrindo a maior parte da polpa & 8 \\
\hline Ausente & 0 & Longa oblonga & 7 & Cobrindo toda a polpa & 9 \\
\hline
\end{tabular}


estudado, considerando-se o conjunto de acessos trabalhado, de acordo com a fórmula abaixo. Este índice também foi utilizado na caracterização morfológica de uma coleção de germoplasma de soja (Perry \& McIntosh, 1991).

$\mathrm{H}=-\mathrm{p}_{\mathrm{i}} \log _{2}\left(\mathrm{p}_{\mathrm{i}}\right) / \log _{2} \mathrm{n}$

onde:

H é o índice de diversidade de Shannon-Weaver; n, o número de classes de um caráter; $\mathrm{p}_{\mathrm{i}}$, a proporção de acessos na i-ésima classe de um caráter.

Um índice de diversidade baixo indica freqüências alélicas não balanceadas para um caráter individual e, conseqüentemente, polimorfismo baixo.

Noventa acessos não produziram raízes, e não foi possível classificá-los com respeito aos descritores forma de raízes, cor da película externa e cor da polpa. Assim, estes acessos não foram considerados no cálculo das estimativas dos índices de diversidade destes descritores. Por outro lado, esses descritores não foram considerados no processamento estatístico para o agrupamento desses acessos.

\section{Resultados e Discussão}

As distribuições de freqüência e os coeficientes de Shannon-Weaver estimados para cada característica avaliada são mostrados na Tabela 2. Comparando-se com uma amostra ideal, onde toda a variabilidade morfológica potencial da espécie $I$. batatas fosse representada de forma balanceada, ou seja, onde os $\mathrm{H}$ de todos os descritores considerados fossem próximos de 1, pode-se considerar que a coleção da Embrapa-CNPH apresenta polimorfismo alto, já que a maioria dos coeficientes de diversidade $(\mathrm{H})$ calculados para esta amostra são maiores que 0,5 .

Com respeito aos 17 descritores da parte aérea, cinco apresentaram $\mathrm{H}$ menor que 0,5 , enroscamento da planta, cor da folha madura, comprimento das ramas principais, cor secundária da rama, e pubescência da rama. São mantidos, na coleção da Embrapa$\mathrm{CNPH}$, apenas genótipos não-enroscantes, com folhas maduras de cor verde. Estes descritores não mostraram polimorfismo na amostra analisada, e, portanto, não apresentaram utilidade para a discriminação entre os acessos da coleção. $\mathrm{O}$ desequilíbrio na distribuição de freqüência dos outros três descritores levou à diminuição do índice de diversidade. Os marcadores morfológicos da parte aérea que apresentaram maiores coeficientes de diversidade são número de lóbulos da folha e pigmentação de nervuras.
Dos oito descritores morfológicos relativos às raízes, as características associadas à polpa da raiz, cor principal e distribuição da cor secundária apresentaram os menores coeficientes de diversidade. Os descritores associados às raízes com maior polimorfismo foram os que descrevem a cor da película externa, cor principal e a intensidade da cor principal, e não se observou a concentração dos genótipos em classes específicas. As características formato e defeitos também foram úteis na discriminação dos acessos da coleção mantida pela Embrapa-CNPH.

Para demonstrar o processo de identificação de acessos morfologicamente duplicados, um exemplo do resultado da análise de agrupamento é mostrado na Figura 1, considerando-se 29 acessos mantidos na coleção da Embrapa-CNPH. Cerca de $85 \%$ da variabilidade observada foi explicada pelos três primeiros vetores estimados na análise de coordenadas principais, refletindo a separação da amostra em grupos bastante diferentes entre si. Acessos que apresentam coeficiente de similaridade igual a 1 são considerados duplicatas morfológicas. Neste exemplo, foram identificados três grupos de acessos morfologicamente duplicados (GM1, GM2 e GM3). Além disso, foram identificados três acessos com morfologia única (GM0). Quando a totalidade da amostra foi analisada conforme descrito, os três primeiros vetores estimados pela análise de coordenadas principais explicaram cerca de $30 \%$ da diversidade observada, indicando que a variabilidade vai se distribuindo de forma gradual por toda a amostra analisada, e não se observa sua separação em poucos grupos distantes entre si. Foram observados 223 acessos com morfologia única (GM0) e a formação de 33 grupos morfológicos, assim distribuídos: 25 grupos com dois acessos (GM03 - GM08, GM11 GM26, GM28 - GM30), três grupos com três acessos (GM10, GM31, GM33), três grupos com quatro acessos (GM01, GM09, GM27), um grupo com sete acessos (GM32) e um grupo com 23 acessos (GM02). O número total de acessos analisados foi de 324 , e foram identificados 256 tipos morfológicos (223 GM0 + 33 GM). Portanto, 68 acessos têm sua morfologia repetida uma ou mais vezes na coleção, o que representa cerca de $20 \%$ de duplicações morfológicas no BAG/batata-doce. 
Tabela 2. Freqüências dos tipos observados e coeficiente de Shannon-Weaver (H) de cada descritor utilizado na caracterização morfológica da coleção de batata-doce mantida pela Embrapa-Centro Nacional de Pesquisa de Hortaliças, 1999.

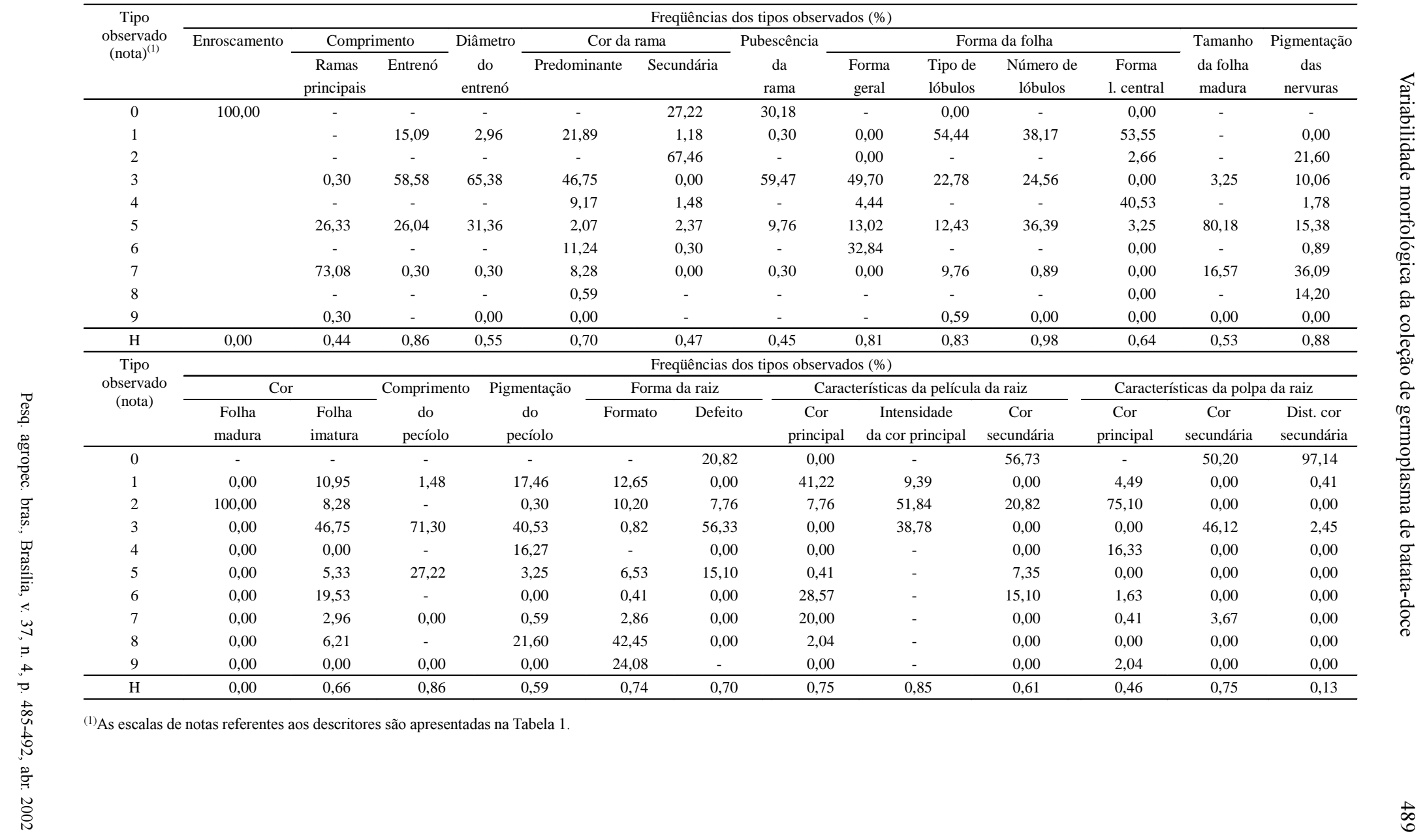


Os resultados obtidos com a caracterização morfológica do BAG/batata-doce têm auxiliado na orientação de outras atividades relacionadas com sua organização. Representam também a primeira etapa no processo de gerar informação sobre o germoplasma nacional de batata-doce.

A decisão de quais acessos devem ser introduzidos na coleção in vitro vem sendo tomada com base no grau de sanidade dos acessos no campo e também nos resultados da caracterização morfológica. Acessos que apresentam morfologia única e que apresentam baixo nível de sanidade na coleção de campo são priorizados para introdução na coleção in vitro. A batata-doce apresenta auto-incompatibilidade, e a produção de sementes botânicas é feita por polinização cruzada, e não se observa a produção de sementes entre acessos geneticamente muito próximos (Martin, 1970a, 1970b; Martin et al., 1974). No pla- nejamento de campos de produção de sementes botânicas visando a conservação a longo prazo do "pool" gênico mantido na coleção, a morfologia dos acessos é verificada, evitando-se o posicionamento de materiais muito similares lado a lado. A caracterização morfológica tem sido complementada com a caracterização molecular do BAG/batata-doce (Ritschel et al., 1999b). Além de confirmar a separação dos grupos morfológicos, a aplicação de marcadores moleculares dentro dos grupos morfológicos identificados permite resolver casos onde a descrição morfológica completa não foi possível. Assim, pode-se definir mais precisamente a identidade de alguns acessos, como aqueles que não produziram raízes durante o processo de caracterização morfológica.

Sob o aspecto de potencial de utilização, as distribuições de freqüência dos descritores morfológicos

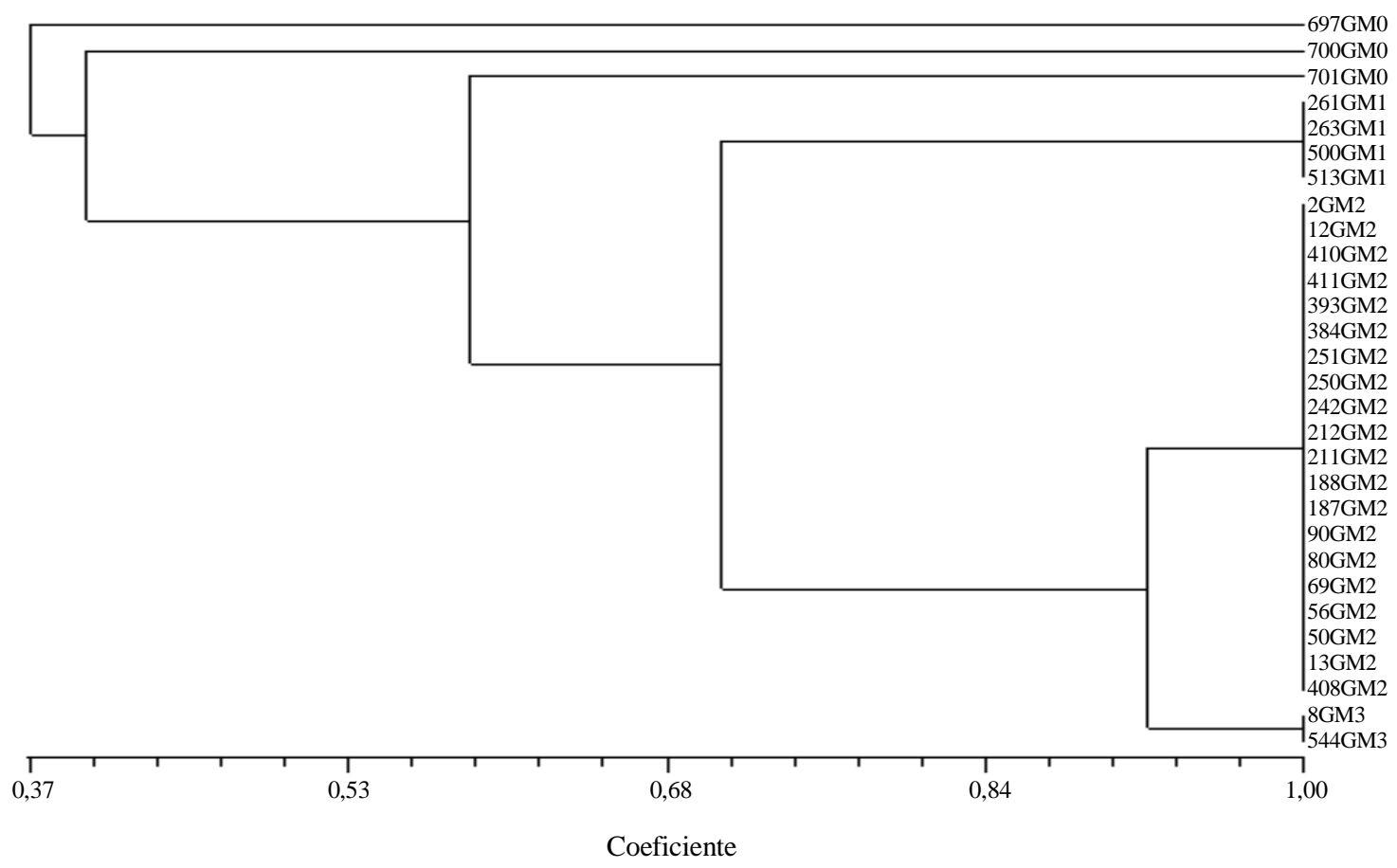

Figura 1. Resultado da análise de agrupamento envolvendo 29 acessos de batata-doce. Na identificação dos materiais, o primeiro número se refere ao registro no Banco Ativo de Germoplasma e o número após as letras GM se refere ao grupo morfológico no qual o acesso foi agrupado. A escala abaixo da figura representa os coeficientes de similaridade calculados entre os acessos. Acessos que apresentam coeficiente de similaridade igual a 1 são considerados duplicatas morfológicas. Neste exemplo, foram identificados três acessos com morfologia única (GM0); quatro acessos foram agrupados no GM1; 20, no GM2 e dois no GM3. 
relacionados às raízes podem ser úteis na escolha de acessos a serem incluídos em ensaios de avaliação. Quando o objetivo é a seleção de materiais para consumo direto ou para industrialização, acessos que apresentam formatos de raiz fora de padrão devem ser evitados, e preferências regionais com respeito tanto às cores da película externa e da polpa ou relacionadas com o potencial de utilização, como na fabricação do doce marron-glacê, também devem ser consideradas.

A parte noroeste da Região Centro-Oeste é considerada centro de diversidade secundária de I. batatas, mas somente $16 \%$ dos acessos do BAG/batata-doce foram coletados nessa Região. Portanto, apenas com base na caracterização morfológica da coleção mantida pela Embrapa-CNPH seria prematuro concluir sobre a variabilidade que a espécie apresenta no Brasil. A organização dos dados de passaporte, análise e comparação da variabilidade mantida em outras coleções brasileiras de batata-doce e a realização de expedições adicionais de coleta de germoplasma de batata-doce, em áreas onde se espera que haja maior variabilidade para a espécie no Brasil, podem contribuir para a resposta desta questão. Considerando-se que a caracterização morfológica deve ser analisada como uma medida indireta da variabilidade total da amostra estudada, a identificação de fenótipos raros, pouco representados em coleções, significa aumento real do "pool gênico" mantido, através de genes relacionados aos descritores utilizados e também a outras características de significado agronômico real ou mesmo potencial. Por outro lado, a identificação do nível de duplicações entre e dentro das coleções nacionais é uma estratégia que facilita o melhor gerenciamento do germoplasma mantido, incluindo o processo de conhecimento dos acessos sob o aspecto agronômico. A estimativa do coeficiente de Shannon-Weaver para as amostras estudadas permitirá a comparação entre a variabilidade mantida na coleção da Embrapa-CNPH e a mantida em outras coleções nacionais mantidas pela Epagri, IPA e Pesagro. Assim, a caracterização do germoplasma de batata-doce está sendo estendida a outras coleções brasileiras.

\section{Conclusões}

1. Utilizando-se a caracterização morfológica e a análise de agrupamento, foi possível identificar
256 tipos morfológicos na coleção de germoplasma de batata-doce mantida pela Embrapa-CNPH.

2. Sessenta e oito acessos têm sua morfologia repetida uma ou mais vezes na coleção, o que representa cerca de $20 \%$ de duplicações morfológicas.

3. A coleção mantida pela Embrapa-CNPH apresenta polimorfismo alto.

\section{Agradecimentos}

Aos pesquisadores e produtores, que contribuíram na reunião e conservação desta coleção de germoplasma; ao Dr. José Amauri Buso, pelas sugestões durante a condução dos trabalhos e pela revisão criteriosa deste manuscrito; ao técnico agrícola Ornélio Guedes da Silva, pelo apoio na execução das atividades de conservação e caracterização do $\mathrm{BAG} /$ batata-doce.

\section{Referências}

AUSTIN, D. F. The taxonomy, evolution and genetic diversity of sweet potatoes and related wild species. In: INTERNATIONAL POTATO CENTER (Lima, Peru). Exploration, maintenance and utilization of sweet potato genetic resources. Lima, 1988. p. 27-60.

BEUSELINCK, P. R.; STEINER, J. J. A proposed framework for identifying, quantifying and utilizing plant germplasm resources. Field Crops Research, Amsterdam, v. 29, p. 261-272, 1992.

CRUZ, C. D.; REGAZZI, A. J. Modelos biométricos aplicados ao melhoramento genético. Viçosa: Imprensa Universitária, 1994. 390 p.

FRANKEL, O. H.; BENNET, E. (Ed.). Genetic resources in plants: their exploration and conservation. Oxford: Blackwell, 1970. 554 p.

HALCOMB, J.; TOLBERT, D. M.; JAIN, S. K. A diversity analysis of genetic resources in rice. Euphytica, Dordrecht, v. 26, p. $441-450,1977$

HORTON, D.; PRAIN, G.; GREGORY, P. High level investment return for global sweet potato research and development. CIP Circular, Lima, v. 17, n. 3, p. 1-11, 1989.

HUAMÁN, Z. (Ed.). Descriptors for sweet potato. Rome: International Board for Genetic Resources/Centro Inter- 
nacional de la Papa/Asian Vegetable Research and Development Center, 1991. 134 p.

HUAMÁN, Z. Morphologic identification of duplicates in collections of Ipomoea batatas. Lima: International Potato Center, 1992. 28 p. (CIP Research Guide, 36).

HUAMÁN, Z.; PUENTE, F. de la. Development of a sweet potato gene bank at CIP. CIP Circular, Lima, v. 16, p. 1-10, 1988.

JANA, S.; SINGH, K. B. Evidence of geographical divergence in Kabuli chickpea from germplasm evaluation data. Crop Science, Madison, v. 33, p. 626-632, 1993.

JONES, A. Quantitative inheritance of ten vine traits in sweet potatoes. Journal of the American Society for Horticultural Science, Mount Vernon, v. 94, n. 4, p. 408-410, 1969.

JONES, A.; STEINBAUER, C. E.; POPE, D. T. Quantitative inheritance of ten root traits in sweet potatoes. Journal of the American Society for Horticultural Science, Mount Vernon, v. 94, p. 271-275, 1969.

KRESOVICH, S.; McFERSON, J. R. Assessment and management of plant genetic diversity: considerations of intra and interspecific variation. Field Crops Research, Amsterdam, v. 29, p. 185-204, 1992.

LI, Y.; WU, S.; CAO, Y. Cluster analysis of an international collection of foxtail millet (Setaria italica (L.) P. Beauv.). Euphytica, Dordrecht, v. 83, p. 79-85,1995.

MARTIN, F. W. Self and interspecific incompatibility in the Convolvulaceae. Botanical Gazette, Chicago, v. 131, n. 2, p. 139-144, 1970a.

MARTIN, F. W. Sterility in some species related to the sweet potato. Euphytica, Dordrecht, v. 19, p. 459-464, 1970 b.

MARTIN, F. W.; JONES, A.; RUBERTE, R. M. A wild Ipomoea species closely related to the sweet potato. Economic Botany, New York, v. 28, p. 287-292, 1974.

MIRANDA, J. E. C.; FRANÇA, F. H. O programa de pesquisa de batata-doce no Centro Nacional de Pesquisas de Hortaliças. In: SEMINÁRIO SOBRE A CULTURA DA BATATA-DOCE, 1987, Brasília. Anais... Brasília: Embrapa-CNPH, 1987. p. 65-74.
PEETERS, J. P.; MARTINELLI, J. A. Hierarchical cluster analysis as a tool to manage variation in germplasm collection. Theoretical and Applied Genetics, Berlin, v. 78 , p. 42-48, 1989.

PEETERS, J. P.; WILLIAMS, J. T. Toward better use of genebanks with special reference to information. Plant Genetic Resources Newsletter, Roma, v. 60, p. 22-32, 1984.

PERRY, M. C.; McINTOSH, M. S. Geographical patterns of variation in the USDA soybean germplasm collection: I. Morphological traits. Crop Science, Madison, v. 31, n. 5, p. 1350-1355, 1991.

RABBANI, M. A.; IWABUCHI, A.; MURAKAMI, Y.; SUZUKI, T.; TAKAYANASHI, K. Variation and the relationship among mustard (Brassica juncea) germplasm from Pakistan. Euphytica, Dordrecht, v. 101, p. 357-366, 1998.

RITSCHEL, P. S.; HUAMÁN, Z.; LOPES, C. A.; MENÊZES, J. E.; TORRES, A. C. Catálogo de germoplasma de batata-doce: I. Coleção mantida pela Embrapa Hortaliças. Brasília: Embrapa-CNPH, 1999a. $47 \mathrm{p}$.

RITSCHEL, P. S.; LOPES, C. A.; HUAMÁN, Z.; FERREIRA, M. E.; FRANCA, F. J.; MENÊZES, J. E.; TEIXEIRA, D. M. C.; TORRES, A. C.; CHARCHAR, J. M.; THOMAZELLI, L. Organização do banco ativo de germoplasma de batata-doce: situação atual e perspectivas. In: QUEIROZ, M. A. de; GOEDERT, C. O.; RAMOS, S. R. R. (Ed.). Recursos genéticos e melhoramento de plantas para o Nordeste brasileiro: versão 1.0. Disponível em: <http:www.cpatsa.embrapa.br $>$. Acesso em: 23 nov. $1999 \mathrm{~b}$.

ROHLF, F. J. NTSYS-PC: numerical taxonomy and multivariate analysis system: version 1.7. Nova York: Exeter Software, 1992. Não paginado.

SINGH, S. P.; GUTIERREZ, J. A.; MOLINA, A.; URREA, C.; GEPTS, P. Genetic diversity in cultivated common bean: II. Marker-based analysis of morphological and agronomic traits. Crop Science, Madison, v. 31, p. 23-29, 1991.

STRAUSS, M. S.; PINO, J. A.; COHEN, J. I. Quantification of diversity in ex-situ plant collections. Diversity, Bethesda, v. 16, p. 30-32, 1989. 